\title{
Research on the teaching mode of chemical experiment in primary school based on cooperative learning
}

\author{
Xiantong Yang ${ }^{\mathrm{a}}$, Qiang Wang ${ }^{\mathrm{b}}$ and Runjie Zhang ${ }^{\mathrm{c}}$, \\ Elementary Education College, Capital Normal University, Beijing, 100048, China \\ a.906191707@qq.com,b.qwchem@gmail.com, c.3986@cnu.edu.cn \\ *corresponding author
}

Keywords: Cooperative learning, Chemical experiments, Teaching model, Science in elementary school

\begin{abstract}
Chemical experiment is an important way to acquire scientific knowledge. Carrying out chemical experiment teaching through cooperative learning plays an important role in cultivating pupils' scientific literacy. However, the existing chemical experiment teaching in elementary school has weak cooperative awareness and unclear role positioning in the group. These problems hinder the scientific learning of primary school students. This study analyzed the advantages of the chemical experiment teaching mode from the perspective of cooperative learning. Based on the principles of chemical experiment teaching from the perspective of cooperative learning, this study proposed a new mode of cooperative learning for primary school chemistry experiments, and provided cases of cooperative learning for primary school chemistry, so as to explore how to improve students' scientific literacy.
\end{abstract}

\section{Introduction}

Chemical experiment is the basic method of studying and learning material and its change, and is an important way to cultivate scientific inquiry. Chemical experiment plays an important role in developing students' core accomplishment of chemistry. It is helpful to stimulate students' interest by using chemical experiments in learning chemistry, and it could create lively teaching situations, help students understand and master chemical knowledge and skills, inspire students' scientific thinking, train students' scientific methods, cultivate students' scientific attitudes and values. ${ }^{[1]}$ However, at present, there are weak cooperative awareness and unclear role positioning in primary school chemistry experiment teaching. The individual difference of students is obvious, the class is difficult to balance; the topics discussed in the group are not concentrated and the scientific concept is not clear. ${ }^{[2]}$ In order to solve the existing problems in chemistry experimental teaching in primary schools, it is necessary to innovate the existing cooperative learning model. 
The experimental teaching of chemistry in primary schools has inherent attributes of cooperative learning. Firstly, the classroom inquiry activities are designed according to the academic research and social collaboration model of scientists, and the academic learning tasks of primary school students are promoted through social interpersonal interactions. Secondly, through the formation of learning groups, a close and interdependent relationship is constructed, in which individuals interact with other individuals or groups in the environment and make use of each other's resources and skills. By asking each other for information, evaluating each other's ideas, supervising each other's work and other strategies, the learning effect of each person can be optimized, and then the overall academic goals can be achieved ${ }^{[3]}$.Finally, cooperative learning has a solid theoretical foundation of philosophy, sociology and psychology ${ }^{[4]}$. Its advantages lie in the integration of two seemingly different goals, academic training and interpersonal communication. It realizes various educational goals through a learning process.

The inherent requirement of the experiment task: Ross believes that good cooperative learning tasks need high intelligence, strong creative and open results. ${ }^{[5]}$ The selection of experimental context in the experimental projects should accord with the requirement of good cooperative learning tasks, by setting up the problems in the real environment and taking cooperative learning, to find the path for solving the problem and toward the goal of training goal.

\section{Advantages of Experimental Teaching Model Based on Cooperative Learning}

\subsection{To Enhance Cooperation Awareness and Build Partnership}

The study shows that the learning environment and atmosphere significantly influence the degree of students' knowledge acquisition ${ }^{[6]}$. The higher the degree of social support, the higher the students' academic performance.

Firstly, cooperative learning creates positive learning psychology. The experimental teaching based on cooperative learning creates a learner-centered learning environment and breaks the teacher-centered scientific teaching mode. A supportive learning community for all members of the group is established in the class with group performance as the evaluation standard, which improves the social psychological atmosphere in the class, creates a win-win learning environment and increases the possibility for all students to successfully complete homework. In it, each team member's ability has been strengthened, students have a strong sense of belonging, and all students' learning has been effectively promoted. In the competitive mono-group experimental teaching mode, students tend to focus on their individual performance and their position in the class, which leads to students' tension, anxiety and self-doubt. Because competition leads to a zero-sum competition, excellent students receive all the rewards and recognition, while ordinary students are always at a disadvantage and lose confidence and interest. The success of a few students leads to the decrease of the chances of success of the majority of students, which often leads to mutual exclusion and even hostility between classmates. Students isolate and criticize the "teacher's pet" for good grades, which is bad for their development and growth. Such an environment, which emphasizes that each individual does better than others, leads to negative perceptions of human nature.

Secondly, cooperative learning highlights the positive atmosphere of peer relations, and brings into play the role of interpersonal interaction in promoting learning. Complete the experimental 
project in groups. Members cooperate with each other, rely on each other, share ideas, learn from each other, encourage each other and make collective decisions for the common learning goal. Students are free to express their opinions and explore their ideas without fear of failure or criticism, allowing students to explore the rules in a safe and harmonious learning atmosphere.

\subsection{To Respect Individual Differences and Balance Classroom Structure}

Firstly, it is necessary to teach students according to their aptitude. Using individualized teaching to find out effective teaching strategies for solving individual differences has been one of the main challenges faced by education staff. Individual differences can be controlled through personalized teaching or ability groups. Cooperative learning has the advantage of solving such problems, because it has the potential to accommodate individual differences in the class. Individual differences are directly used to promote learning, because individual differences are the source of students' learning.

The second is to create conditions for teachers to objectively evaluate students and evaluate learning effects. Every teacher needs a fair and accurate method to evaluate students' learning and cannot simply calculate a class member's score from test percentages and assignments, because it will deprive students of other important attributes brought by laboratory course. In security cooperation team environment, students are free to discuss their understanding of the problems and operation.The teachers can discuss and listen to their operations from the team, collect related information about the students understand, assessment team's understanding of important scientific concept in the experiments and promptly clarify and misgivings problems existing in the experimental process. ${ }^{[7]}$ It provides many opportunities for the teachers to evaluate students' explain and ideas.

\subsection{To Focus on Problem Solving and Cultivate Thinking Methods}

The main purpose of experimental teaching is to let students improve their understanding of scientific laws through experiments.firstly the experimental teaching mode based on cooperative learning is conducive to the cultivation of scientific thinking. Students could complete the challenging task through cooperative learning through active participation. ${ }^{\left[{ }^{8]}\right.}$ It can shift the responsibility of learning to the students in the group, to do so,students will define and solve problems in their own words, rather than copy teachers and textbooks to provide them with material.Students in groups will talk about more and ask more than students who are not in groups.The students tried to explain their understanding of a subject or explained by trying to understand companion content, effectively strengthen the scientific information communication. Learners are in an active position in the learning environment. When students really participate in the learning process, they control the learning by themselves, which exerts a direct positive influence on stimulating students' learning motivation, maintaining learning time and obtaining good learning results. Therefore, students will become more and more addicted to scientific exploration. When disagreements arise between team members on cooperation, they will try to resolve the conflict in your mind by making a more in-depth thinking and adjusting the understanding of problems. Thus, It will generate a high level of scientific reasoning, strengthen scientific concepts of critical thinking,improve the understanding of science, help to further develop 
scientific problem solving strategy, strengthen students' lasting attention in science, increase the chance of student work in the science of future success.

Second, cooperative learning has cultivated students' scientific methods. Experiment is an important tool of scientific methods. The main purpose of experiment teaching is to improve students' understanding and grasp of discipline rules through hands-on practice. Collaboration with peers is the way that science works in the real world, and teamwork is essential to the success of science. In collaborative projects, students work together to solve scientific challenges, using algorithms, theories, programs, and concepts to verify their ideas.It is a process that follows exactly the same procedures that a team of scientists does scientific research.It rarely happens in the competitive learning environment where students experiment on their own, or in the step-by-step teaching of recipes or formulations in the laboratory. In addition, cooperative groups tend to extend their learning beyond experimental teaching content, leading to more in-depth learning.

\subsection{To Shape the Right Values and Improve Social Skills}

First, cooperative learning helps to shape students' thinking or orientation of identifying things and distinguishing right from wrong, and to set up correct values. Students who study in cooperative groups develop healthy education values more than competitive and independent learning. Cooperative learning develops friendships, and students are more altruistic, disciplined, caring, compassionate, and responsible than competition-driven teams. Cooperative learning encourages active interdependence, team members are psychologically connected, and help each other in the learning process. Students at lower levels benefit from being helped to become better students, while students with higher abilities benefit from helping team partners with lower abilities to realize their own growth. Successful collaborative learning improves students' abilities, strengthens their beliefs, and makes them believe that they can actually succeed in this course, which is self-efficacy. Cooperative group teaching improves the understanding of diversity among students with different learning styles and abilities, and solves the problem of style differences.

Second, cooperative learning has cultivated students' social skills. One of education's main goals is to prepare for the real world, and experimental teaching based on cooperative learning simulates real life, where students can experience various social roles in learning, enhance responsibilities to others, cultivate respect for humanity, and promote interpersonal relationships. Collaborative learning develops job-related skills such as leadership, verbal and written communication, constructive inquiry, communication of materials, and brainstorming, which are necessary for effective functioning in a work environment. Collaborative learning helps students resolve their differences amicably, and students learn how to challenge their ideas and advocate for their positions through personalized presentations. They also learn about conflict resolution methods that are important in real life.

\section{Experimental Teaching Principles Based on Cooperative Learning}

\subsection{Build Effective Teams}

An efficient team has a strong sense of cooperation and clear role positioning. Cooperative learning is based on the teaching model of groups, which enables students to work together and 
maximize the role of teams. But teachers should take note: cooperative learning neither just bring students together nor expect simple learning activities to occur. It takes four conditions to build an efficient team for cooperative learning. First, it needs clear group goal and individual division of labor. The group must have a clear team goal and the corresponding task that each individual must undertake in order to connect individual responsibility with the group goal. The completion of the experimental project must be assessed not only on the team's responsibility to achieve its goals, but also on each individual's responsibility for their own contribution, that is, not being a "free rider" on someone else's work. Second, it needs positive interdependence. The completion of each experimental project means that the realization of the team's goal is complicated or time-consuming. To be successful, several people need to work together to complete the project. Everyone in the team needs to establish the concept of integrity and integrity. In other words, they have to cooperate or they can't get the job done.

Third, maintain constant face-to-face communication. Students should act in a trusting and trustworthy manner, care about each other's success, encourage and help each other, regularly exchange resources, provide feedback and summarize conclusions. The fourth requirement is smooth team operation. To help students develop skills such as leadership, decision-making, trust building, communication and conflict management, students must constantly assess their team's performance. If there is a problem in the progress of the experimental project, the teacher can help students find the cause, correct the direction and improve the process in a timely manner.

\subsection{Design Questions Properly}

One of the important reasons for the poor effect of cooperative learning is that the task difficulty is not set in place and can be completed without cooperation. Therefore, in experimental teaching, the experimental project should be carefully designed to make it suitable for cooperative learning. First, reality is the source of the problem. The experimental project should be close to life, let students develop interest in solving practical problems and attract students to study. Second, the task should have appropriate difficulty. The experimental project should be fully challenging for students, slightly beyond students' ability, and cannot be completed by students alone, so as to stimulate students' desire for knowledge and improve their learning motivation. Third, the task should be open-ended, multi-answer, or multi-method. Experimental projects with no specific answers or multiple answers tend to encourage individuals to contribute to the team's goals and pool their resources through group activities. The multi-method problem enables the team to solve a problem in different ways, and expands students' thinking and problem-solving ability from different perspectives.

\subsection{Define the Role of Teacher}

With the update of teaching philosophy and the development of information technology, teachers are no longer just as the imparting of knowledge, but as the guide, supporter and collaborator of learning. In experimental teaching, teachers should help schools to focus on topics and define scientific concepts. First, the teacher is the order maintainer of the project team operation. The teacher maintains the current order, is the strict discipline implementation, and guarantees the project team safe and smooth operation. Second, teachers are the creators of experimental 
conditions. ${ }^{[9]}$ Successful team learning requires the careful planning, thoughtful arrangement and comprehensive preparation of teachers to provide all necessary conditions for experiments. Third, teachers are the facilitators of the experimental process. Teachers should actively "look on", observe and record the performance of each team and individual, point out problems, offer consultation, make Suggestions, and give timely psychological support and encouragement. Fourth, teachers are evaluators of experimental results. Based on the completion of the project and the overall performance of the project team, the teacher gives the unified score of the project team, which does not reflect the differences of individuals within the team.

\section{Experimental Teaching Mode Based on Cooperative Learning}

Based on the principle of cooperative learning, an experimental teaching mode based on cooperative learning is proposed. As shown in figure 1.

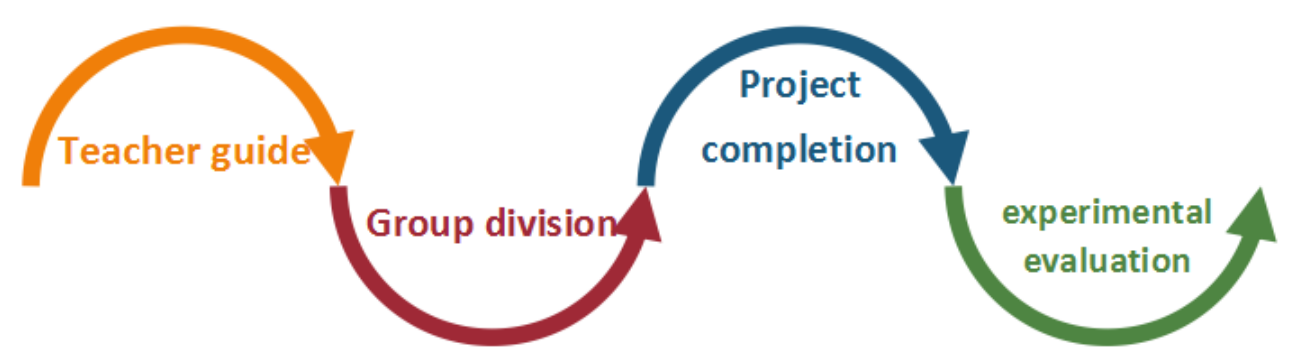

Figure 1: Flow chart of experimental teaching model based on cooperative learning.

\subsection{Experimental Teaching Process}

\subsubsection{Teacher Guidance}

First, the teacher should inform the students to adopt the experimental teaching mode of group cooperation, and give the necessary explanation about cooperative learning. In particular, it should highlight the significance of cooperative learning, motivate students' learning motivation, and emphasize the contents such as group goal, individual responsibility and evaluation method. Second, teachers should introduce the basic skills of team management, communication and conflict resolution, tell students how to cooperate, and emphasize the importance of mutual trust and effective communication. Thirdly, teachers should eliminate the hidden danger of laboratory safety and create a safe experimental environment for students. It is necessary to carry out safety education for students and make them establish a strong safety concept, and train students with basic risk identification and emergency response ability.

\subsubsection{Division of Labor in Groups}

First, create a team. Fully respect students and combine freely according to the principle of free will. However, the heterogeneity within the group should be taken into consideration. Students with different academic performance, ability, gender, personality, specialty and other aspects should be divided into one group as far as possible. The differences and complementarities between 
individuals in the group should be maintained. The size of the group depends on the difficulty of the experimental project and the amount of tasks. At the same time, the homogeneity between groups should be guaranteed, so that each group is at the same starting line, and inter-group competition should be properly maintained. More importantly, cooperation between groups should be emphasized to achieve a higher level of group interaction and achieve a win-win goal.

After the grouping is completed, each group takes over the laboratory space and necessary equipment and counts the signatures. Secondly, the division of labor within the group must be done well. Under the guidance of the teacher, the team members fully discussed, decomposed the experimental task, and took responsibility according to their own advantages. Teachers can assign roles according to the nature of work, and can also assign tasks according to the content of work. Different roles should be rotated in different experiments to ensure that everyone can get comprehensive exercise. The group leader who responsible for the management of the whole team and the teachers is the key role, and the members of the group responsible for the group leader.

\subsubsection{Project Completion}

Firstly, based on the division of labor, the work plan and team operation mechanism should be formulated, and corresponding rules and disciplines should be clarified. Students' behaviors should be regulated by rules, standards and procedures to ensure smooth communication and active support between members. Second, the work plan includes experimental project design, data collection, experimental operation, observation record, result collation, report writing, result presentation, etc. A series of learning activities should be carried out according to the work plan, safety and environmental protection should always be regarded as the important link, and group and group discussion should be carried out throughout. Thirdly, teachers and team members monitor and feedback the whole process, conduct regular evaluation, timely find problems, adjust and improve team activities to ensure the completion of teaching objectives.

\subsection{Evaluation of Experimental Teaching}

\subsubsection{Group Self-evaluation}

Group self-evaluation includes the group leader's evaluation of each member, mutual evaluation among team members, and individual self-evaluation. The main evaluation requirements include the positive attitude, smooth communication, standard and rigorous operation, and the completion of tasks.

\subsubsection{Mutual Evaluation between Groups}

The group was informed of the information through the usual observation and communication, the joint conference between the groups, the summary and communication conference, etc., and the group was evaluated mainly on whether the team was united and cooperative, and whether the team members were active and serious. 


\subsubsection{Teacher Evaluation}

As an active "bystander", the teacher guides and assists the entire experimental teaching process, mainly giving evaluation from experimental results and team performance, and giving overall group scores. Teachers should give evaluation and scores based on the actual experimental data and interpretation of the data, and the experimental results refer to the experimental records and reports. Reference group self-evaluation, intergroup evaluation, and teachers' own observation records were used to evaluate and score the team performance. Main evaluation points include whether the team collaboration is smooth, whether the technical operation is standard, whether the safety protection is in place, and whether the experimental results are up to standard.

\section{Experimental Teaching Cases}

In order to introduce the teaching model of cooperative learning more specifically and clearly, a case study of "research and development of an interdisciplinary course integrating science and art" in the experimental school of the affiliated high school of Renmin university of China was introduced detailedly . ${ }^{[10]}$

\subsection{Experimental teaching process}

The main purpose of this teaching case is that students, under the guidance of teachers, work in groups and cooperate, and finally complete the learning project. Enrich their knowledge and concepts, improve their ability to conduct scientific experiments, and increase their interest in scientific experimental courses.

First of all, this experiment needs to integrate scientific experiment and art hands-on dyeing, including some complicated operational steps. The project has certain difficulty, so it needs the guidance of teachers. One is that before this lesson, the students have understood and participated in the group cooperation learning, and the teacher has made relevant explanations on the basic skills of team management, communication and conflict resolution. Second, before formally starting the experiment, the teacher has explained the cooperative learning mode and meaning of this lesson, and emphasized the group goal, individual responsibility, evaluation method and other contents. Third, the teacher has done the pre-experiment, removed the potential danger of the laboratory, ensured the safety of the experiment, and strengthened the students' awareness of laboratory safety and the ability to deal with the danger. Second, do a good job in the form of the group division of labor and project content within the group division of labor. In terms of the division of labor outside the group, the teacher divides the class into six groups according to the knowledge base, operational ability and interest specialty between the students. In terms of division of labor within the group, based on the requirements of different tasks such as overall planning, information arrangement, experimental operation, safety guarantee, environmental protection, etc., the teacher arranged different roles for each member of the group, such as team leader, information collator, experimental operator, safety guarantee officer, environmental protection supervisor, etc. In this way, grouping cooperation achieves unity in form and content.

Finally, the students followed the disciplinary requirements and the planning process of scientific inquiry and art creation during the experiment. While serious, students actively communicate their 
problems and discoveries within and between groups. While when the students start to use their brains, the teacher and the teaching assistant always play the role of the guide between the groups, always pay attention to the students' questions, and answer the students' questions in time.

\subsection{Evaluation of experimental teaching}

First of all, because the students' works are so many shapes and forms that it is impossible to grade each student accurately with quantitative methods, this experiment adopts the method of demonstration and explanation to evaluate the works qualitatively.

Secondly, in terms of the order of evaluation, the group should be evaluated first to see who can win the approval of more students in the group. Then make a group selection to see whose results will win the recognition of more people in the class. Teachers also evaluate students' work. In order to gain the recognition of more people, each student presenting the work needs to introduce and give a speech. For example, some students showed their own color rings and claimed to be inspired by the orbits of the planets in the solar system.

Finally, the teacher explained the evaluation criteria. For example, the evaluation criteria in this experiment include internal standards and external standards, and internal standards include the beauty of the work, the degree of innovation of the work, and the connotation of the work. External standards include experimental attitude, communication, operational standards, division of labor and cooperation, etc. Teachers play an important role in making, implementing and reviewing standards in evaluation.

\section{Conclusions}

Experimental teaching based on cooperative learning accommodates differences among students, creates an active learning environment for students, and provides students with opportunities for deep learning. It links the improvement of student participation with more real scientific practice and clear learning objectives in the laboratory which is one of the powerful methods to improve grades, stimulate cognitive development, improve self-esteem and improve interpersonal relations.[11]In order to achieve better experimental teaching results, when designing and implementing cooperative learning activities, first of all, optimize group composition, task structure, student role and group norms, embed positive interdependence, reward and evaluation mechanisms, clarify role positioning and strengthen cooperation awareness. Second, by establishing positive interdependence and individual accountability, ensure that each student contributes and takes responsibility for learning, fully respects individual differences and gives play to everyone's strengths to balance the classroom structure. Finally, the group orientation of cooperative learning should be reduced as much as possible, and the learning efficiency of different types of learners should be improved.

\section{References}

[1] Ministry of Education of the People's Republic of China.(2017) Curriculum standards for general high school chemistry.Beijing: people's education press,72-73.

[2] Dai Tingting.(2016)Problems and Countermeasures in Scientific Cooperative Learning in Primary Schools.Good parents, 46,44 . 
[3] Chiu, M. M. (2008)"Flowing toward correct contributions during groups' mathematics problem solving: A statistical discourse analysis". Journal of the Learning Sciences,3,415-463.

[4] Wang Tan.(2002)On the Basic Concept of Cooperative Learning.Educational Research,2,68-72.

[5] Ross, J.,\& Smythe, E. (1995)Differentiating Cooperative Learning to Meet the Needs of Gifted Learners: A Case for Transformational Leadership. Journal for the Education of the Gifted, 19, 63-82.

[6] Kohn, A. (1986). No Contest: The Case Against Competition. Boston, MA: Houghton-Mifflin. 27.

[7] Alico, R.(1997)Enhancing the Learning in Microbiology through Cooperative Learning. The Annual Meeting of the Mid-Atlantic Association of Micro- biologists, Montgomery, MD.

[8] Gabbert, B., Johnson, D. \& Johnson, R. (1986)Cooperative learning, group-to-individual transfer, process gain and the acquisition of cognitive reasoning strategies. Journal of Psychology, 120, 265-278.

[9] ZHANG Rui-Jie,GU Xing-Hai,LIU Rong-Min.(2017) Role-Playing as A Pedagogical Approach in Chemical Experiment teaching.Chinese Journal of Chemical Education, 6,29-34.

[10] X. T. Yang,M. M. Zhang,Y. Yue,Y. H. Zhao,Han Hui,Q. Wang.(2018)Researching and Developing Interdisciplinary Course That Integrates Science and Art(CISA). American Journal of Educational Research and Reviews,3,26.

[11] Bergin, S. D.,Murphy, C.,\&Shuilleabhain, A. Ni.(2017)Exploring Problem-based Cooperative Learning in Undergraduate Physics Labs: Student Perspectives.European Journal of Physics,2,6-19. 